\title{
Identity and Urban Values for Sustainable Design
}

\author{
Natalina Carrà ${ }^{1, ~ a ~}$ \\ ${ }^{1}$ Mediterranea University of Reggio Calabria, Dept of Heritage, Architecture, Urban planning \\ Sal Melissari, Feo di Vito, 89124 Reggio Calabria, Italy \\ 2ncarra@unirc.it
}

Keywords: Urban heritage, Identity, Transformations, Sustainable Enhancement.

\begin{abstract}
The urban historical contexts have suffered, over the years, different phenomena related to the processes of transformation, sometimes with positive and tangible effects on the quality and the urban model, sometimes negative and/or inappropriate. The present moment proposes again in all its aspects the need to engage a reflection on the phenomenon of transition of these forms, design expressions as possible answer as well as regards the aspects related to the identity nature of places, better known as what we call cultural sustainability. The concept of identity related to the notion of cultural sustainability, which affirms the non-repeatability of some physical and social forms/structures, is the object of these design expressions.
\end{abstract}

\section{Introduction}

The process that determines the trends and the urban developments caused by actions of transformation is not linear. The periods of crisis can occur when in the settlements there are disequilibriums between the needs of the settled community and the urban environment or when the socio-economic and technological evolution prevail the balances that have always characterized contexts with specific identity values, fixed antique/primitive morphologies and certain functions.

Among the tasks of the experts referred to the "discipline" and also to national policies, it is that one of keeping under control, monitoring these processes and being able to recognize the moment when it is necessary an inversion, through encouragement or adoption of new praxises. The phenomena of transition are some of the signs of a reaction to the current period, and must be observed and promoted because they have the characteristic of being able to take place in everyday life, developing from processes that arise from below. The observation of these events makes it possible to propose specific design approaches and to address the regulatory apparatus in order to promote and encourage the taking place changes.

The urban historical contexts have suffered, over the years, different phenomena related to the processes of transformation, sometimes with positive and tangible effects on the quality and the urban model, sometimes negative and/or inappropriate. The present moment proposes again in all its aspects the need to engage a reflection on the phenomenon of transition of these forms, design expressions as possible answer as well as regards the aspects related to the identity nature of places, better known as what we call cultural sustainability. The concept of identity related to the notion of cultural sustainability, which affirms the non-repeatability of some physical and social forms/structures, is the object of these design expressions. The defined identity, also, as the particular imprint that the environmental character succeeds to confer, in terms of spatial and temporal synthesis, to the structures of the place [1]. An identity that it is possible to interpret in the housing/architecture building custom, in the use of techniques and local resources, and, more generally, in the relationship among morphology, topology and geometry. A kind of invariant (environmental) to be understood both as a physical limit, and as a structural aspect linked to the housing customs of the places. In this panorama it is well-fitting the concept of resilience, deriving from the ecological lexicon that is the ability of a system to resist and maintain its working despite a change or a shock from the outside. The system in this case is the historical city in its whole and resilience must be the result to whom the transition process of these places should tend at this exact historical moment. 


\section{Resilience and identity value of the places}

The resilience of urban historical contexts is proved by the complexity of the urban history of these places, often theater and cradle of many civilizations and able to absorb, mix and rearrange, in their thousands-year old stories, a plurality of urban and social cultures that have progressively interested them, invested, edited, and to which they have almost always been able to respond (resilience), producing new and more elaborate socio-cultural synthesis and urban forms.

The transformations of these places start from a new hypothetical evolutionary scenario, just of transition - the term transition identifies a process of transformation that could be developed to respond to an hypothetical scenario of change next to us - in which the emerging functional, ecological and social issues will occur predominantly.

To make less traumatic this step (transition), it should be necessary to make recognizable and to promote the processes that give rise to resilience that is the ability to adapt to changes, both in the lifestyles of people, and in the constituent features of the urban context (structure, shape, functions), through a progressive and gradual adaptation to the changes of the urban environment in its whole.

Recent events demonstrate the real dangers that current uncontrolled interventions of physical transformation of the cities produce: gentrification, ghettoizing, destruction of heritage and memory and identity of places. It is therefore necessary at the threshold of the twenty-first century that a conscious renewal of urban values corresponds to the change in the strategies of urban transformation. A resilient city changes its historical identity with the change, old and new values, rationality and emotions, conservation and development [2]; a city founded on the principle of resilience is, therefore, a city that evolves according to the cultural conditions of departure, accepting the new elements imposed by the change, increasing, through the awareness, their ability to adapt; in this sense, resilience assumes the meaning of flexibility, adaptation that does not imply, therefore, the restoration to an initial state, but the restoration functionality through the change and adaptation. A regeneration understood as resilience, is, so, a process more dedicated to environment and resource consumption, beyond mere redevelopment.

\section{Identity value of the places in the sustainable design of the historical city}

The processes of urban transformation, now more than ever have to face, especially in cities with strong historical identity connotations, with more or less consistent traces of a legacy that emerges as tangible and intangible assets, archaeological strata, trails and signs. The stratifications of memory, especially fundamental characteristic of Mediterranean cities, put the focus on the value of cultural-historical heritage, fundamental component to which the actions and design strategies must be directed to contrast the threats of the effects of standardization of lifestyles and careless processing places. These cities are a kind of palimpsest on which the imprint of the historical past as evidence of their own identity. Every historical city is a complex, heterogeneous layered, a structural and material amalgam, an inseparable overall resource.

The characterization of historical city is understood, therefore, both as a system of values, and a set of functions, which should be substantiated in a perfect integration between quantity and quality. In fact, it is often as a centrality of centrality, both because it is the concentration of value and functions systems, and for the symbolic, identity and psychological investment that tradition has set down. The debate and the experiences of the last decades have shown strongly that the future of the historical city is an integral part of the future idea of the whole existing city, of the identity and role that is recognized to all its parts and their mutual relations and interdependences: without this horizon of meaning and action, the reorganization of the historic city may not reveal its potentiality of regeneration or evenmore it risks to undermine its resources.

The translatability of the ancient space into the modern needs brings with it significant risks that can be summarized in the problem of interpretation and evaluation of the space. The ancient city is left to re-use, both globally-and the fact that the Old Town has preserved often, in fact, its centrality in regard to the entire contemporary city, it is the most obvious demonstration-either in its various component; this means that the space-large or small it is-is able to offer itself to a different use, 
changing over the time: in this sense, the ancient space has its own strength and extraordinary resistance. But at the same time, its availability to transformation may be an inherent weakness, because the operation of re-use may have degenerative aspects that deform or destroy these contexts [3].

These aspects are particularly clear in Mediterranean and European contexts, where the cultural resource is widespread and represents a potential boost to improve local economies and the cities and regions attractiveness. Cities and territories are not, however, an inert and stable deposit of resources and goods, but a "capital" of inalienable and inimitable value, unique that encompasses cultural, historical and artistic peculiarities to protect and enhance in a perspective of sustainable development.

From the physical point of view, trying to view urban stratifications as a kind of thickness, the image focused more easily is made from a series consisting of sections that, cutting with geometric precision both buildings and empty spaces, returns the relationship between the "above the surface and below the surface". Thickness has also another meaning frequently used, it is used when referring to the substance, weight, solidity and quality of contents, in this case exactly oriented to the urban structure, these contents are indeed the traces of cultures and ages that physical stratifications prove. Moving from abstraction of the imagination to concrete, real perception of urban space, it is, therefore, possible to verify that it is exactly in this situation (characteristic only of urban Mediterranean area) that the more complex and interesting conditions of the contemporary city historical project occur, thickness so as stratification, but also as value and historical memory.

A very interesting thesis is advanced by Jacques Derrida; in Of Grammatology he asserts that it is possible another form of memory, a memory that is no longer about fragments or representations or abstractions, but something he defines track. The track is the presence of an absence [4].

Historical knowledge, in the relationship with the city and the territory, is the result of a reflection that enacts the theories of even different sectors, notices that the enhancement of urban heritage is no more only artistic/aesthetic, but it must achieve and reach " hermeneutic criteria", investing in knowledge as interpretation; accumulating fragments of pre-existence is not the same of accumulating memory and the re-actualization of design actions, confirms that remembering can take place only in the present.

The interest, therefore, is the relationship between heritage and design, history and design, and it refers to the wider horizon of reference of the recycling/urban and landscape recover of the existing, whose importance is now emerging in relation to the need of intervention in contexts that have been constructed "curing" and strengthening the existing rather than consuming more land, more "territory". The built heritage, in this case the urban heritage is here taken in its more inclusive meaning that is not limited to that is inherited from the past and history, but that, on the contrary, continues to build and reorganize itself during the time. It is in this perspective that the heritage becomes possible ambit of transformation, achieved through the project, as well as scene of signs and memories disclosed through its reading, definition, decoding. Designing, planning on the existing, is not possible without an analyzed knowledge of its history and from a recognition of the memory from which it was produced and composed.

The conceptual path can be summarized in three key words: heritage, modification, care; these represent the speculative framework of reference in which the memory, identity and history appear as the operative conditions of the process, if put in a dialectical relationship with the possible/suitable transformations (modification). This means that the project may affect the heritage transforming/changing it, with actions that allow the lifetime that is its preservation over the time and thus its continuity/persistence of memory.

The theoretical positions to support these attitudes depart from the idea of heritage expressed by Françoise Choay [5], according to which, the wide consent in favor of the preservation of historical heritage, is related to scientific, aesthetic, commemorative, social, urban "values", of which such heritage is carrier in advanced societies. But also to the positions of Joseph Rykwert [6], who argues that the design is a conceptual elaboration, that however begins from the recovery of tradition. The relationship between past and present, and between built form and social thought are essential links 
that accompany the theories of Rykwert, which also states that the urban areas are a synthesis of historical, ecological, social processes with metaphorical signs of transmission of memory.

The theme of change, as it has been developed starting from the positions of Bernardo Secchi [7], focuses on the evolution of city planning and modern architecture for their being rich and complex and therefore requiring different design methods, but only for some ways opposite to that of the past, in which the emphasis is placed primarily on the problem of meaning, that is, that one of the relations with what is part of the context, of its factuality and materiality, its history, its function in the process of social reproduction, its constitutive rule. At a more specific level it means to build plans " finer grained ", devoid of demonstrative character, which do not aspire to transcend the situation in which they are produced, which do not claim to legitimacy through an instrumental and bureaucratic apparatus delivered by the discursive tradition, but that articulate the space of discourse with more limited and defined thematizations; plans that lose partially their institutional character, usually abstract and independent from specific purposes, which select the issues of design starting from the specificity of places, their positional character, referring to an idea of bounded rationality. Concepts and positions extremely countertrend, but highly illuminating and acceptable in the current period of transition, fainter grain plans must be understood within the logic of projects extremely more careful and flexible than the plans that have preceded them. Also the concept of care initially theorized by Pier Luigi Cervellati [8] is referred to a change of direction that starts simply from the re-reading of the roots of the history of territory, of its way of being - and being been- in order to trigger an urban reorganization able to "recover "and" keep" those qualities that have always characterized the city as an alternative model to fight the uniformity. Care of the city, so, understood as resistance to the progressive evacuation of the urban centers and to the uniformity of the living spaces, that offer comfortable scenarios but no identity.

Care understood as interventions of building renewal preserving the sign of the roots of a city history, in order to set the future without destroying the memory. The most recent positions of Nicola Emery [9] refine the concept of care understood as a form of plausible relationship between utility and form, in other words, the relationship with the architecture and so the city is connected by the author through the ancient theorists's reflections, mainly as relational, as something to cure in the sense of creating relationships, free spaces, bring energy, to relate to the essence of man that requires today a sustainable relationship with the environment that surrounds it. The concept is that aesthetics should join the care, aiming to relational aspect of the project and its ecologically sustainable relation with the environment in which it inserts.

\section{Sustainable enhancement and the "fainter grain plans"}

The valuation of heritage, whether it is an artifact, or a context or an intangible permanence attributes the recognition of its importance, its weight in the system of values of a given area and in a given community. The sustainable exploitation of the heritage of historic urban contexts has become in recent years a real opportunity of investment, that, in addition to the educational function affirms its fundamental role in regenerative processes of the tissues, therefore of material and tangible recovery of the historical memory of places.

Regenerating, promoting access, improve quality of life, are the fundamental principles of the interventions on historic urban environments, which are emerging recently with the aim of increasing the quality of places and life of the inhabitants and users. New forms of exploitation and new logics of intervention more closely connected to the experience factor, to the sustainability of management solutions and to the participation of local communities.

The terms sustainable and compatible, although abused, identify a sensitivity to the environment -physical and cultural- of the city and invite us to create the conditions to favour creativity and innovation. There is, that is to say, a renewed focus on forms of soft redevelopment through which it is possible to reposition itself within the competitive local and international system.

Strategies for sustainable development in these areas must be understood, therefore, not as simply protection and preservation of goods and resources, but as an action based on a more general process of economic revitalization, where the increase in value of the resources and their 
organization in a system, focusing on accessibility and usability criteria, may be the key to generate new attractivity and, therefore, social and economic relaunch.

The urban fabrics, regarded as living organisms in their continuous contaminations, see in the relationship between old and new, a comparison that it offers itself to various possibilities and discussions. Both at the macro scale (historical center and urban fabric) and at the micro scale (the artifact in its process of conservation and refurbishment), the historical city is called to change its conformation and configuration, in a tight relationship between history and technology. There are, however, inherent in the nature of its morphology/urban form, some factors we can define about conditioning, which do not make easy the physical and structural interventions in its inside. These restrictions, in fact, restrict and affect some types of interventions. The first factor is related to the physical nature of the places, namely the urban structure and its fabrics, often intricate and compact that affect and constrain the plot of the mobility system, which results to be among the issues of greater impact in the projects of transformation of these contexts.

The second is related to the sustainability of the functions; being able to stem the monofunctionality, often exclusively linked to commercial activities, it is the other issue that often requires considerable attention for the good success of the project. A further factor of conditioning is the entire urban landscape with all that composes it; working on quality and identity of the image of the perceived landscape is another important challenge for these new project forms. And finally, another conditioning factor is the strong appeal that these contexts have with all that comes from it: improper uses, deterioration and neglect of places, disproportionate increase in land value of the properties. Common problems sustain conditioning factors: degradation, scraping and neglect of places and functions, loss of attractiveness and identity, social degradation, lack of basic services; autoreferentiality; poor accessibility.

All this determines effects now known, which can be defined as real risk factors inherent in the processes of physical and social transformation of urban historical contexts: it is referred to phenomena of gentrification, but also to museification with relative spectacularization of memory and identity.

\section{Projects of sustainable enhancement}

The projects of sustainable enhancement, through processes of development that are not only a whole of measures aimed exclusively at increasing the economic value of areas and properties, but they pursue wider goals of social, economic and cultural redevelopment and revitalization of the urban context to which they are referred, consider the presence and the implementation of a complex system of planning which includes interventions, proposals and policies with a lower degree of complexity than those identified by other types of instruments. These are, in fact, "open" projects because they define a general strategy in the medium and long term for the historical city and its enhancement within the urban fabric, with scenarios and strategies that represent, namely, the reference frame that should guide coherently future proposals in line with the objectives to be pursued.

The scenarios/planning visions materialize in interventions affecting:

- the urban structure and thus the physicality of the place;

- the behaviors of people attending/inhabit the context;

- the behaviors of the companies that operate in it.

The arrangement of these interventions in the urban space takes into account the evolution of the city over the course of history, that is of its physical and immaterial memory to highlight, also, as exactly the criticalities of the urban structure can become circumstances to create opportunities of redevelopment and trigging virtuous processes of revitalization.

The identification of the scenarios is quite functional to a pronounced characterization of the future perspective and the simultaneous quantification of the weight of the various functions brought into play by the strategical proposed policies within each scenario.

The general objectives, common to the possible scenarios of reference are: 
- to enhance the historical contexts in their whole;

- to make the potentialities of the urban transformations of the historical context functional to the new requirements of economic and social development of the city;

- to promote the recovery and the restoring of the historic building complexes abandoned or little used;

- to improve urban and settlement quality;

- to create opportunities for growth and qualification of the local economy.

To pursue these objectives, it should address the issue of the historical context in the future of the city starting from the real strengths of the system, creating the conditions for a transformation compatible with the ongoing development planning and seeking to combine government intervention with the private sector, so as to produce positive effects on quality life and local economic development.

In order, therefore, to obtain that the process is not reduced to a simple real estate development, or to a building restoration or urban make-up, it is necessary not only to leverage existing and potential resources, but also to respond to the deficiencies of the urban fabric and to the instances coming from the socio-economic context. We speak, therefore, of a strategy for overall enhancing, able to put together physical, social, economic and cultural interventions. The various interactions among the social, ecological and economic indicate that these processes of sustainable development go from selective intervention to overall development strategy, assuming the role of a key strategy to bring quality and identity in urban contexts of value, an extraordinary opportunity to face the challenges of the current socio-economic and cultural changes.

\section{References}

[1] E. De Carli, E. Scatà (a cura di): Antologia critica degli scritti di Saverio Muratori, Firenze, Alinea Ed. (1991)

[2] L. Fusco Girard, Sustainability, Creativity, Resilience: Toward New Development Strategies of Port Areas through Evaluation Processes, International Journal of Sustainable Development, (2010)

[3] M. G. Cusmano: Oggi parliamo di città. Spazio e dimensioni del progetto urbanistico, FrancoAngeli, Milano (2002)

[4] J. Derrida: Of Grammatology, Baltimore, The Johns Hopkins University Press (1997)

[5] F. Choay: L'allegoria del patrimonio, Officina Edizioni (1995)

[6] J. Rykwert: La seduzione del luog. Storia e futuro della città, Einaudi, (2003)

[7] B. Secchi: Le condizioni sono cambiate, in: Casabella n. 298-99, (1984), pp. 8-13

[8] P. L. Cervellati: L'arte di curare la città, Il Mulino (2000)

[9] N. Emery: Progettare, costruire, curare. Per una deontologia dell'architettura, Casagrande, (2010) 